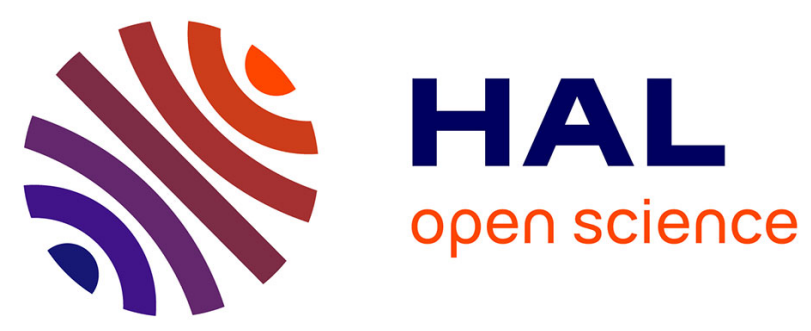

\title{
Distal Pancreatectomy with Celiac Axis Resection (Modified Appleby Procedure) and Arterial Reconstruction for Locally Advanced Pancreatic Adenocarcinoma After FOLFIRINOX Chemotherapy and Chemoradiation Therapy
}

Pierre-Emmanuel Colombo, François Quenet, Pierre Alric, Anne Mourregot, Mathias Neron, Fabienne Portales, Philippe Rouanet, Guillaume Carrier

\section{- To cite this version:}

Pierre-Emmanuel Colombo, François Quenet, Pierre Alric, Anne Mourregot, Mathias Neron, et al.. Distal Pancreatectomy with Celiac Axis Resection (Modified Appleby Procedure) and Arterial Reconstruction for Locally Advanced Pancreatic Adenocarcinoma After FOLFIRINOX Chemotherapy and Chemoradiation Therapy. Annals of Surgical Oncology, 2021, 28 (2), pp.1106-1108. 10.1245/s10434020-08740-y . hal-02882669

\section{HAL Id: hal-02882669 \\ https://hal.science/hal-02882669}

Submitted on 19 Aug 2021

HAL is a multi-disciplinary open access archive for the deposit and dissemination of scientific research documents, whether they are published or not. The documents may come from teaching and research institutions in France or abroad, or from public or private research centers.
L'archive ouverte pluridisciplinaire HAL, est destinée au dépôt et à la diffusion de documents scientifiques de niveau recherche, publiés ou non, émanant des établissements d'enseignement et de recherche français ou étrangers, des laboratoires publics ou privés. 


\title{
Distal Pancreatectomy with Celiac Axis Resection (Modified Appleby Procedure) and Arterial Reconstruction for Locally Advanced Pancreatic Adenocarcinoma After FOLFIRINOX Chemotherapy and Chemoradiation Therapy
}

\author{
Pierre-Emmanuel Colombo, MD, $\mathrm{PhD}^{1}$, François Quenet, $\mathrm{MD}^{1}$, Pierre Alric, $\mathrm{MD}, \mathrm{PhD}^{2}$, \\ Anne Mourregot, $\mathrm{MD}^{1}$, Mathias Neron, MD', Fabienne Portales, $\mathrm{MD}^{3}$, Philippe Rouanet, $\mathrm{MD}, \mathrm{PhD}^{1}$, and \\ Guillaume Carrier, $\mathbf{M D}^{1}$
}

${ }^{1}$ Department of Surgical Oncology, Institut du Cancer de Montpellier (ICM), Montpellier, France; ${ }^{2}$ Department of Thoracic and Vascular Surgery, Arnaud de Villeneuve Hospital, Montpellier, France; ${ }^{3}$ Department of Medical Oncology, Institut du Cancer de Montpellier (ICM), Montpellier, France

\begin{abstract}
Background. Resectability of pancreatic carcinoma (PC) is directly linked to vascular extension (Tempero MA et al. in J Natl Compr Canc Netw 15(8):1028-1061, 2017. http s://doi.org/10.6004/jnccn.2017.0131; Isaji S et al. in Pancreatology 18(1):2-11, 2018. https://doi.org/10.1016/j.pan. 2017.11.011). Involvement of the celiac axis (CA) is typically a contraindication to surgery. High postoperative morbidity and subsequent poor prognosis have been observed in this case, especially for contact $>180^{\circ}$ requiring arterial resection (Tempero MA et al. 2017). Recent medical advances in PC treatment, such as FOLFIRINOX-based chemotherapy eventually followed by chemoradiation therapy, offer the potential to select tumour for surgery and to obtain a negative-margin resection even in case of unresectable PC at diagnosis (Suker M et al. in Lancet Oncol 17(6):801-10, 2016. https://doi.org/10.1016/ s1470-2045(16)00172-8; Pietrasz D et al. in Ann Surg Oncol 26(1):109-117, 2019. https://doi.org/10.1245/s1043 4-018-6931-6). A major pathologic response has been
\end{abstract}

P.-E. Colombo, MD, PhD

e-mail: Pierre-Emmanuel.Colombo@icm.unicancer.fr observed in more than $20 \%$ of patients after this treatment and is associated with an improved survival (Suker M et al. 2016; Pietrasz D et al. 2019). This evolution allows aggressive surgical strategies with the possibility of longterm disease control for patients showing a good response to induction treatment.

Patient. This video presents the case of a 66-year-old man diagnosed with a locally advanced ductal adenocarcinoma of the pancreatic body with a $360^{\circ}$ involvement of the CA and the hepatic artery. After eight courses of FOLFIRINOX chemotherapy and a capecitabin-based chemoradiation, a surgical exploration was planned for potential resection.

Technique. The key steps of the procedure are presented, i.e. surgical exposition, assessment of resectability with frozen sections of peri-arterial tissues, en bloc resection (Strasberg SM et al. in Surgery 133(5):521-527, 2003. h ttps://doi.org/10.1067/msy.2003.146), and primary end-toend arterial reconstruction.

Conclusion. A modified Appleby operation for locally advanced PC is a technically challenging but feasible procedure in experienced teams. It offers the possibility of en bloc R0 resection of a locally advanced PC with the potential of long-term disease local control. This video may help surgeons to perform this complex intervention.

Resectability of pancreatic carcinoma (PC) is directly linked to vascular extension. ${ }^{1,2}$ Involvement of the celiac axis (CA) is typically a contraindication to surgery. High postoperative morbidity and subsequent poor prognosis 
have been observed in this case, especially for contact $>180^{\circ}$ requiring arterial resection. ${ }^{1}$ Recent medical advances in PC treatment such as FOLFIRINOX-based chemotherapy eventually followed by chemoradiation therapy offer the potential to select tumour for surgery and to obtain a negative-margin resection even in case of unresectable PC at diagnosis., ${ }^{3,4,5}$ A major pathologic response has been observed in more than $20 \%$ after this treatment and is associated with an improved survival., This evolution allows aggressive surgical strategies with the possibility of long-term disease control for patients showing a good response to induction treatment.

Appleby described the first CA resection in locally advanced gastric cancers in $1953 .^{6}$ The procedure included en bloc gastrectomy, distal pancreatectomy, and splenectomy associated with the resection of the CA and the hepatic artery (HA) proximal to the gastroduodenal artery (GDA). Liver vascularisation is then based on the retrograde arterial blood flow through the GDA and also on the possibility of an aberrant HA emerging from the superior mesenteric artery (SMA) or a preserved left gastric artery. ${ }^{6}$ However, a risk of severe liver ischemia and gallbladder necrosis was reported in the postoperative period. ${ }^{6}$ The modified Appleby procedure was subsequently described in 1976 by Nimura et al. for locally advanced body or tail PC, allowing en bloc resection of the $\mathrm{CA}$ and the tumour without gastric resection. ${ }^{7,8}$ As in the original procedure, the liver arterial supply is also based on the retrograde blood flow from the SMA through the pancreaticoduodenal arcades and the GDA. If the perfusion is not adequate, the common HA needs to be reconstructed to prevent the complications of hepatic ischemia.

To overcome this issue, preoperative embolization of the common HA to enlarge the collateral pathways has been described and is currently recommended. ${ }^{9}$ Distal pancreatectomy with CA resection is then frequently performed without arterial reconstruction after preoperative embolization and its risks, including postoperative arterial hemorrhage or thrombosis. HA embolization is currently associated with embolization of the splenic and left gastric arteries to reinforce perigastric arcades limiting postoperative ischemia of the stomach. However, recent series observed a residual risk of liver and/or biliary ischemia in the postoperative period, and also a high rate of pancreatic leak. ${ }^{10}$ Cholecystectomy is then recommended to avoid postoperative necrotic cholecystitis. If the peroperative evaluation of the liver perfusion through the GDA is not adequate, or in case of peroperative damage to the pancreaticoduodenal arcades, arterial reconstruction is required to prevent hepatic or gastric ischemia. In this case, arterial reconstruction may be compromised by preoperative embolization leaving coils in the CHA.
The alternative of the preoperative embolization strategy is the arterial reconstruction showing interesting surgical outcomes with R0 resection and primary arterial anastomosis or graft bypass. ${ }^{1-14}$ Various approaches to vascular reconstruction have been described in the literature. In our experience, an end-to-end primary arterial anastomosis was possible in the majority of cases, between the aorta or the CA stump and the remaining HA without venous or prosthetic graft interposition. This primary reconstruction is particularly feasible if a residual CA stump remained after a margin-negative resection, as shown in the presented video. Direct reconstruction between different arterial supplies (the middle colic artery, a conserved left gastric artery, or an iliac external artery) and the proper HA have also been described. ${ }^{14}$ Arterial reconstruction allows an arterial supercharge of the liver inflow without compromising arterial vascularisation of the pancreaticoduodenal region. Primary anastomosis is preferable to interposition grafting along the pancreatic stump to reduce infectious or thrombotic complications and to reduce the number of arterial anastomoses. If direct anastomosis is not feasible, a graft bypass is required. In this case, an autologous graft using the saphenous vein or the inferior mesenteric vein is preferred to the interposition of a synthetic graft besides the pancreatic stump. In all cases, patient selection, attentive analysis of vascular anatomy, and management in experienced centres are the key steps of this procedure.

ACKNOWLEDGMENTS The authors thank Luis Ocampo for editorial assistance.

DISCLOSURES Pierre-Emmanuel Colombo, François Quenet, Anne Mourregot, Mathias Neron, Fabienne Portales, Philippe Rouanet, and Guillaume Carrier have no disclosures to declare.

\section{REFERENCES}

1. Tempero MA, Malafa MP, Al-Hawary M, et al. Pancreatic Adenocarcinoma, Version 2.2017, NCCN Clinical Practice Guidelines in Oncology. I Natl Compr Canc Netw. 2017;15(8):1028-61. https://doi.org/10.6004/jnccn.2017.0131

2. Isaji S, Mizuno S, Windsor JA, et al. International consensus on definition and criteria of borderline resectable pancreatic ductal adenocarcinoma 2017. Pancreatology. 2018;18(1):2-11. https://d oi.org/10.1016/j.pan.2017.11.011

3. Suker M, Beumer BR, Sadot E, et al. FOLFIRINOX for locally advanced pancreatic cancer: a systematic review and patient-level meta-analysis. Lancet Oncol. 2016;17(6):801-10. https://doi.org/ 10.1016/s1470-2045(16)00172-8

4. Pietrasz D, Turrini O, Vendrely V, et al. How does chemoradiotherapy following induction FOLFIRINOX improve the results in resected borderline or locally advanced pancreatic adenocarcinoma? An AGEO-FRENCH multicentric cohort. Ann Surg Oncol. 2019;26(1):109-17. https://doi.org/10.1245/s10434018-6931-6 
5. Strasberg SM, Drebin JA, Linehan D. Radical antegrade modular pancreatosplenectomy. Surgery. 2003;133(5):521-7. https://doi. org/10.1067/msy.2003.146

6. Appleby LH. The coeliac axis in the expansion of the operation for gastric carcinoma. Cancer. 1953;6(4):704-7. https://doi.org/ 10.1002/1097-0142(195307)6:4\%3c704::aid-cncr2820060410\%3 e3.0.co;2-p

7. Nimura $Y$, Hattori $T$, Miura $K$, et al. Resection of advanced pancreatic body-tail carcinoma by Appleby's operation. Shujutu 1976;30:885-9.

8. Bonnet S, Kohneh-Shahri N, Goere D, Deshayes I, Ayadi S, Elias D. Indications and surgical technique of Appleby's operation for tumor invasion of the celiac trunk and its branches [in French]. $J$ Chir (Paris). 2009;146(1):6-14. https://doi.org/10.1016/j.jchir.2 009.02.002

9. Kondo S, Katoh H, Shimizu T, et al. Preoperative embolization of the common hepatic artery in preparation for radical pancreatectomy for pancreas body cancer. Hepatogastroenterology. 2000;47(35):1447-9.

10. Cesaretti M, Abdel-Rehim M, Barbier L, Dokmak S, Hammel P, Sauvanet A. Modified Appleby procedure for borderline resectable/locally advanced distal pancreatic adenocarcinoma: A major procedure for selected patients. J Visc Surg. 2016;153(3):173-81. https://doi.org/10.1016/j.jvisesurg.2015.11.014
11. Bockhorn M, Burdelski C, Bogoevski D, Sgourakis G, Yekebas EF, Izbicki JR. Arterial en bloc resection for pancreatic carcinoma. Br J Surg. 2011;98(1):86-92. https://doi.org/10.1002/bjs. 7270

12. Amano H, Miura F, Toyota N, et al. Is pancreatectomy with arterial reconstruction a safe and useful procedure for locally advanced pancreatic cancer? J Hepatobiliary Pancreat Surg. 2009;16(6):850-7. https://doi.org/10.1007/s00534-009-0190-7

13. Amano R, Kimura K, Nakata B, et al. Pancreatectomy with major arterial resection after neoadjuvant chemoradiotherapy gemcitabine and S-1 and concurrent radiotherapy for locally advanced unresectable pancreatic cancer. Surgery. 2015;158(1):191-200. h ttps://doi.org/10.1016/j.surg.2015.02.016

14. Latona JA, Lamb KM, Pucci MJ, Maley WR, Yeo CJ. Modified appleby procedure with arterial reconstruction for locally advanced pancreatic adenocarcinoma: a literature review and report of three unusual cases. $J$ Gastrointest Surg. 2016;20(2):300-6. https://doi.org/10.1007/s11605-015-3001-2 